\title{
Hyphoderma pinicola sp. nov. of $H$. setigerum complex (Basidiomycota) from Yunnan, China
}

\author{
Eugene Yurchenko ${ }^{1}$ and Sheng-Hua $\mathrm{Wu}^{2^{*}}$
}

\begin{abstract}
Backgroud: Hyphoderma setigerum (Fr.) Donk is a white-rot wood-decaying corticoid fungal species. It occurs worldwide from tropical to temperate regions. However, taxonomic studies in recent decades showed that $H$. setigerum is a species complex with four separate species, before this study.

Results: Hyphoderma pinicola sp. nov. was collected on dead wood of Pinus yunnanensis Franch. in the temperate montane belt at 2200-2400 m altitudes, in Yunnan Province of China. Within the H. setigerum complex this new taxon is distinguished by having 2-sterigmate basidia, long basidiospores, and nearly naked septocystidia. A description and illustrations of this new species are provided, along with a key to five species of the H. setigerum complex. Phylogenetic reconstruction based on 5.8S-ITS2 sequences indicated that $H$. pinicola belongs to the $H$. setigerum complex and has a separate position within the clade including H. subsetigerum and H. setigerum s.s. Bayesian inference of phylogeny based on two datasets, ITS and 285 nuclear ribosomal DNA sequences, confirmed the independent status of $\mathrm{H}$. pinicola.
\end{abstract}

Conclusion: Morphological and phylogenetic studies showed that $H$. pinicola represents a fifth species of H. setigerum complex.

Keywords: Corticioid fungi; Meruliaceae; Polyporales; Taxonomy

\section{Background}

Hyphoderma Wallr. is the largest genus of Basidiomycota with resupinate non-poroid basidiomata. Currently, 103 species are recognized under Hyphoderma in Index Fungorum (Kirk, 2014). According to Dai (2011), 24 species of Hyphoderma s.l. (including Mutatoderma (Parmasto) C.E. Gómez and Peniophorella P. Karst.) were listed in the mycobiota of China. Hyphoderma setigerum (Fr.) Donk occurs worldwide from tropical to temperate regions. However, taxonomic studies in recent decades showed that $H$. setigerum is a species complex with four species. A new species belonging to the $H$. setigerum complex is described in the present paper. This new taxon is based on specimens collected in 2001 on dead branches of Pinus yunnanensis Franch., from the temperate montane belt of Yunnan Province, China.

\footnotetext{
* Correspondence: shwu@mail.nmns.edu.tw

${ }^{2}$ Department of Biology, National Museum of Natural Science, Taichung 404, Taiwan

Full list of author information is available at the end of the article
}

\section{Methods}

Reference herbarium materials and study of the morphology

The specimens studied of this new species are deposited in the herbaria TNM and MSK (herbarium acronyms follow Index Herbariorum, http://sweetgum.nybg.org/ih). The isolate is kept in the culture collection of TNM.

Description of macromorphology is based on dry basidiomata. Microscopic measurements and drawings were made from material mounted in $3 \% \mathrm{KOH}$ water solution. Melzer's reagent was used to examine amyloidity or dextrinoidity of spore walls, but also to study crystalline incrustations on hyphae, or in the hymenium. Cyanophily of the spore wall was tested in cotton bluelactophenol solution. To determine average spore size, 30 randomly selected spores from a squash basidioma preparation were measured.

\section{DNA extraction, amplification, and sequencing}

Nuclear ribosomal DNA sequences of Hyphoderma were analyzed in addition to morphological study. The material for DNA isolation was mycelium grown in pure culture 
(Wu 0108-36), and basidioma pieces taken from herbarium specimens (TNM F13635, TNM F13637). Both kinds of material were homogenized in liquid nitrogen. DNA was extracted with Plant Genomic DNA Extraction Miniprep Kit (Viogene, Taiwan), according to manufacturer's protocol. Primer pair ITS1/ITS4 was used for amplification of internal transcribed spacer region, including ITS1, 5.8S, and ITS2, under PCR conditions, described in White et al. (1990). The DNA fragment of ribosomal large subunit gene (28S), was amplified with primers LR0R/LR5 (Moncalvo et al., 2000), following PCR settings as described in Wu et al. (2007). Amplifications were run on a Mastercycler Gradient 5331 thermal cycler (Eppendorf, Germany). Amplification products were purified with a PCR-M Clean Up kit (Viogene) and sequenced with an ABI PRISM BigDye Terminator Cycle Sequencing Ready Reaction kit on ABI 3730 DNA sequencer (Applied Biosystems, USA). The resulting sequences were deposited in NCBI GenBank (Table 1).

\section{Sequence alignment and reconstruction of phylogeny}

The datasets were composed of the sequences obtained in this study and taken from GenBank (Table 1), with the aim to elucidate phylogenetic distances between the new taxon and other Hyphoderma species. Two species of Mutatoderma, earlier known under Hyphoderma, were added to both $5.8 \mathrm{~S}$-ITS2 and 28S datasets. From about 50 ITS sequences of $H$. setigerum available in GenBank, we selected those representing the main clades within this species complex (Nilsson et al., 2003). The selected taxa in the ingroup belong to residual polyporoid clade of Agaricomycetes (Binder et al., 2013). Phanerochaete sordida (P. Karst.) J. Erikss. \& Ryvarden, a member of phlebioid clade, was selected as an outgroup in both datasets.

Sequences were aligned on-line in MAFFT v. 7 (http:// mafft.cbrc.jp/alignment/server), using E-INS-i strategy for ITS and G-INS-i for 28S (Katoh et al., 2009). Before alignment, ITS1 and 28S segments were cut from the sequences where needed. Sequences that were too short were removed from the datasets after preliminary alignments. Final datasets were edited manually in MEGA v. 3.1 (Kumar et al., 2004). Ready data matrices, together with resultant phylograms, were deposited in TreeBase (http://purl.org/phylo/treebase/phylows/study/TB2:S16046). The best-fit models of nucleotide evolution were estimated by MrModeltest v. 2.3 (Nylander, 2004), with Akaike Information Criterion as a relative quality measure of the model (Posada and Buckley, 2004). The input file for MrModeltest was generated in PAUP* v. 4.0b10 (Swofford, 2002).

Bayesian analysis of phylogeny was performed in MrBayes v. 3.2.1 (Ronquist and Huelsenbeck, 2003). Both 5.8SITS2 and 28S datasets were individually analyzed in two independent runs, each with four $\mathrm{MC}^{3}$ chains running for
1 million generations, with tree and parameter sampling every 500 generations. Burn-in was as default setting (discarding $25 \%$ of samples). The datamatrix of 5.8S-ITS2 was analyzed with different sets of parameters for two partitions, 5.8S and ITS2, according to best-fit models. FigTree v. 1.3.1 was used to view and capture the resultant phylograms and CorelDraw v. 9 for drawing the images.

\section{Results}

A key to species of Hyphoderma setigerum complex

1. Conspicuous capitate cystidia with naked, bulbous apices present, up to $14 \mu \mathrm{m}$ wide apically, coarsely encrusted below the apex

H. nudicephalum

1 Cystidia more or less cylindrical, seldom with naked capitate apex, but the apical bulb not exceeding $8 \mu \mathrm{m}$ in width 2

2. Basidia 2-sterigmate

2. Basidia 4-sterigmate 3 ... 4

3. Basidiospores reaching 15-17.5 $\mu \mathrm{m}$ long, often suballantoid; basidia 25-32 $\mu \mathrm{m}$ long; septocystidia naked or weakly encrusted, often with thin (up to $0.5 \mu \mathrm{m})$ wall H. pinicola

3. Basidiospores 10-12 $\mu \mathrm{m}$ long, only a little depressed adaxially; basidia 17-25 $\mu \mathrm{m}$ long; septocystidia heavily encrusted, typically with thick (up to $1 \mu \mathrm{m}$ ) wall

\section{H. bisetigerum}

4. Basidiospores 6-8 $62.8-3.2 \mu \mathrm{m}$; known from Taiwan, Japan, China H. subsetigerum

4. Basidiospores 7-10(-14) × 3-5(-6) $\mu \mathrm{m}$; worldwide H. setigerum

\section{Hyphoderma pinicola}

Yurchenko \& Sheng H. Wu, sp. nov. Figures 1 and 2.

\section{MycoBank}

804684

\section{Holotype}

China. Yunnan Prov., Hoching County, Sungkuei, alt. $2200 \mathrm{~m}$, on dead corticated branch of Pinus yunnanensis, coll. S.H. Wu \& S.Z. Chen, 1 Aug 2001, Wu 0108-32 (TNM F13637; isotype in MSK).

\section{Etymology}

Specific epithet refers to the host preference (Pinus).

\section{Diagnosis}

Basidioma thin; hymenial surface chalky white, warted; septocystidia scattered, almost naked and often thin- 
Table 1 Taxa used in this study, along with their specimen /strain numbers, locality information and GenBank accession numbers

\begin{tabular}{|c|c|c|c|c|}
\hline \multirow[t]{2}{*}{ Species name } & \multirow[t]{2}{*}{ Isolate / Specimen voucher } & \multirow[t]{2}{*}{ Country of origin } & \multicolumn{2}{|c|}{ GenBank accession no. for nrDNA } \\
\hline & & & 5.8S-ITS2 & 285 \\
\hline Hyphoderma cremeoalbum & / NH 11538 (GB) & Turkey & DQ677492 & DQ677492 \\
\hline Hyphoderma definitum & / GEL 2898 & & - & AJ406509 \\
\hline Hyphoderma definitum & / FCUG 2426 & Russia (Krasnodar krai) & AJ534293 & - \\
\hline Hyphoderma definitum & / NH 12266 (GB) & Russia & DQ677493 & DQ677493 \\
\hline Hyphoderma granuliferum & / KHL $12561(\mathrm{O})$ & Costa Rica & JN710545 & JN710545 \\
\hline Hyphoderma incrustatum & KHL 6685 / & & - & AY586668 \\
\hline Hyphoderma litschaueri & / NH 7603 (GB) & Canada & DQ677496 & DQ677496 \\
\hline Hyphoderma litschaueri & / CFMR:DLL2011-050 & USA & KJ140573 & - \\
\hline Hyphoderma macaronesicum & E09/57-9 / TFC:Mic.15981 & Canary Islands & HE577027 & - \\
\hline Hyphoderma medioburiense & / NH 10950 (GB) & Spain & DQ677497 & DQ677497 \\
\hline Hyphoderma nemorale & EM 2793 / & & - & AY586669 \\
\hline Hyphoderma nudicephalum & / TMIC 33708 & Japan & AJ534264 & - \\
\hline Hyphoderma nudicephalum & / TMIC 50048 & Japan & AJ534265 & - \\
\hline Hyphoderma nudicephalum & / FCUG 2949 & Japan & AJ534266 & - \\
\hline Hyphoderma nudicephalum & / TMIC 30479 & Japan & AJ534267 & - \\
\hline Hyphoderma nudicephalum & Wu 9508-225 / & China & AJ534268 & - \\
\hline Hyphoderma nudicephalum & Wu 9307-29 / & Taiwan & AJ534269 & - \\
\hline Hyphoderma nudicephalum & / TMIC 50049 & Japan & AJ534270 & - \\
\hline Hyphoderma nudicephalum & / GEL 4727 & & - & AJ406510 \\
\hline Hyphoderma obtusiforme & / KHL 1464 & & JN572909 & - \\
\hline Hyphoderma obtusiforme & / KHL 11105 & & JN572910 & - \\
\hline Hyphoderma obtusum & JS 17804 / & & - & AY586670 \\
\hline Hyphoderma occidentale & KHL 8469G / & & - & AY586674 \\
\hline Hyphoderma occidentale & / KHL 8477 (GB) & Sweden & DQ677499 & DQ677499 \\
\hline Hyphoderma pinicola* & Wu 0108-30 / TNM F13635 & China & KJ885179 & KJ885180 \\
\hline Hyphoderma pinicola* & Wu 0108-32 / TNM F13637 & China & KJ885181 & KJ885182 \\
\hline Hyphoderma pinicola* & Wu 0108-36 / TNM F13643 & China & KC928278 & KC928279 \\
\hline Hyphoderma prosopidis & E09/58-9 / ARIZ:H.H. Burdsall 8479 & USA & HE577029 & - \\
\hline Hyphoderma roseocremeum & NH 10545 / & & - & AY586672 \\
\hline Hyphoderma setigerum & / GEL4001 & & - & AJ406511 \\
\hline Hyphoderma setigerum & / FCUG 1688 & Finland & AJ534272 & - \\
\hline Hyphoderma setigerum & / FCUG 1200 & Norway & AJ534273 & - \\
\hline Hyphoderma setigerum & KHL 8544 / & & - & AY586673 \\
\hline Hyphoderma setigerum & FCUG 1264 / NH 8544 (GB) & Sweden & FN907905 & FN907905 \\
\hline Hyphoderma setigerum & FCUG 2499 / & Argentina & GQ409515 & - \\
\hline Hyphoderma setigerum & FCUG 2530 / & Argentina & GQ409516 & - \\
\hline Hyphoderma setigerum & FCUG 3038 / & South Africa & GQ409517 & - \\
\hline Hyphoderma setigerum & FCUG 3037 / & South Africa & GQ409518 & - \\
\hline Hyphoderma setigerum & CFMR FP101976 / & USA & GQ409519 & - \\
\hline Hyphoderma setigerum & CFMR HHB9443 / & USA & GQ409520 & - \\
\hline Hyphoderma subtestaceum & CFMR HHB11620 / & USA & GQ409521 & - \\
\hline Hyphoderma subtestaceum & CFMR MJL1536 / & USA & GQ409522 & - \\
\hline
\end{tabular}


Table 1 Taxa used in this study, along with their specimen /strain numbers, locality information and GenBank accession numbers (Continued)

\begin{tabular}{|c|c|c|c|c|}
\hline Hyphoderma subsetigerum & Wu 9508-155 / & China & AJ534275 & - \\
\hline Hyphoderma subsetigerum & / TMIC 33552 & Japan & AJ534276 & - \\
\hline Hyphoderma subsetigerum & Wu 9304-18 / & Taiwan & AJ534277 & - \\
\hline Hyphoderma subsetigerum & Wu 9202-15 / & Taiwan & AJ534278 & - \\
\hline Hyphoderma transiens & / NH 12304 (GB) & Sweden & DQ677504 & DQ677504 \\
\hline Mutatoderma heterocystidium ${ }^{* *}$ & / NH 7574 (GB) & Canada & DQ677495 & DQ677495 \\
\hline Mutatoderma mutatum & / NH 12026 (GB) & Russia & DQ677498 & DQ677498 \\
\hline Phanerochaete sordida & / KHL 12054 (GB) & Norway & EU118653 & EU118653 \\
\hline
\end{tabular}

*Data in bold indicate the sequences obtained in this study.

**In GenBank under the name Hyphoderma heterocystidiatum (Burt) Donk.

walled; basidia with two large sterigmata; basidiospores (10-)13-16(-17.5) $\mu \mathrm{m}$ long, predominantly suballantoid.

\section{Description}

Basidiomata effused, membranaceous, 60-150 $\mu \mathrm{m}$ thick. Hymenial surface chalky white, minutely warted (3-4 warts $/ \mathrm{mm}$ ), between warts from the beginning minutely porulose, then continuous, minutely cracking with age. Margin zone up to $1.5 \mathrm{~mm}$ broad, concolorous with the main hymenial surface, abrupt or usually diffuse or slightly fibrillose. Hyphal system monomitic, all hyphae colorless, thin-walled, clamped at all primary septa. Subiculum thin, consisting of thin, fairly compact layer of more or less horizontal hyphae next to the substratum, and loose intermediate layer composed of variously oriented hyphae. Subicular hyphae moderately branched, 3-4.5 $\mu \mathrm{m}$ diam, naked to richly encrusted. Subhymenium not distinctly differentiated from subiculum. Subhymenial hyphae moderately to richly branched, 2.5$3 \mu \mathrm{m}$ diam, moderately to richly encrusted (most incrustation dissolving in $\mathrm{KOH}$ solution). Cystidia of two kinds: (1) septocystidia scattered, projecting, irregularly cylindrical, straight to strongly twisted, simple or branched, with (2-)4-6(-8) and more predominantly clamped septa, apically near cylindrical or subcapitate, 65-180 $\mu \mathrm{m}$ long, up to 7-11 $\mu \mathrm{m}$ broad in swellings and the least $3.5 \mu \mathrm{m}$ broad in constrictions, colorless, moderately thin-walled (walls up to $0.5 \mu \mathrm{m}$ thick) to seldom thick-walled (up to $2 \mu \mathrm{m}$ thick), naked or slightly encrusted, especially in basal part; (2) aseptate cystidia may be found in younger portions, slightly protruding, subcylindrical, $35-45 \times(4.5-) 6-7 \mu \mathrm{m}$, thin-walled, naked. Basidia subcylindrical or narrowly utriform, 25$28(-32) \times 5-6.5 \mu \mathrm{m}$, colorless, thin-walled, naked, with two sterigmata measuring 6.5-7.5(-9) × 1-1.5(-1.8) $\mu \mathrm{m}$. Spores cylindrical to allantoid, rarely slightly sigmoid, $(10-) 13-16(-17.5) \times(3.5-) 4-4.5(-6) \mu \mathrm{m}$ (rarely up to $19.5 \mu \mathrm{m}$ long), colorless, thin-walled, smooth, negative in Melzer's reagent, acyanophilous, with a short rounded apiculus.

\section{Additional specimens examined}

CHINA. Yunnan Prov., Hoching County, Sungkuei, alt. $2200 \mathrm{~m}$, on dead twig of Pinus yunnanensis, coll. S.H. Wu \& S.Z. Chen, 1 Aug 2001, Wu 0108-30 (TNM F13635); Chuhsiung, Tzuhsishan, alt. $2400 \mathrm{~m}$, on dead twig of Pinus sp., coll. S.H. Wu \& S.Z. Chen, 2 Aug 2001, Wu 0108-36 (TNM F13643).

\section{Distribution}

The species is so far known only from the temperate belt in northwest part of Yunnan Province, China.

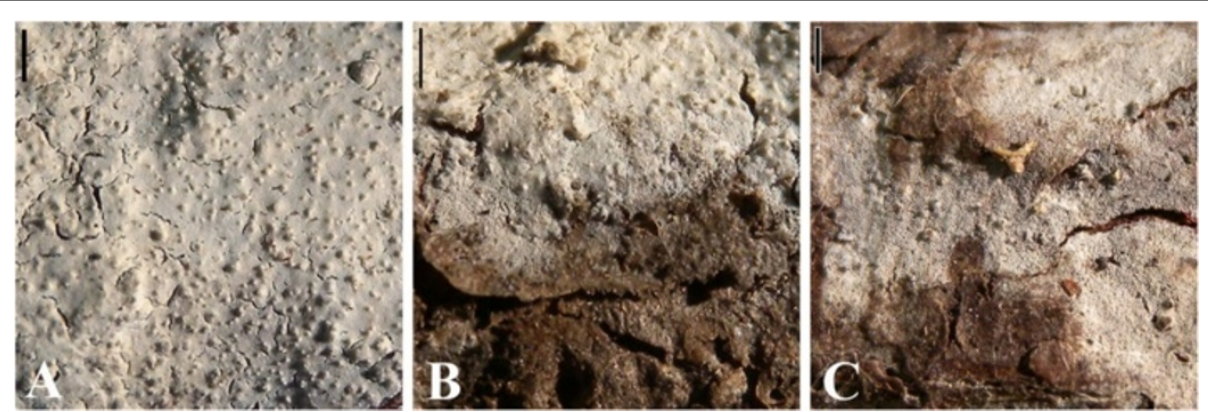

Figure 1 Macromorphology of Hyphoderma pinicola (TNM F13635). A, Basidioma in central part (holotype); B, Basidioma in marginal part (holotype); $\mathbf{C}$, Thin, minutely porulose basidioma. Scale bars $=1 \mathrm{~mm}$. 


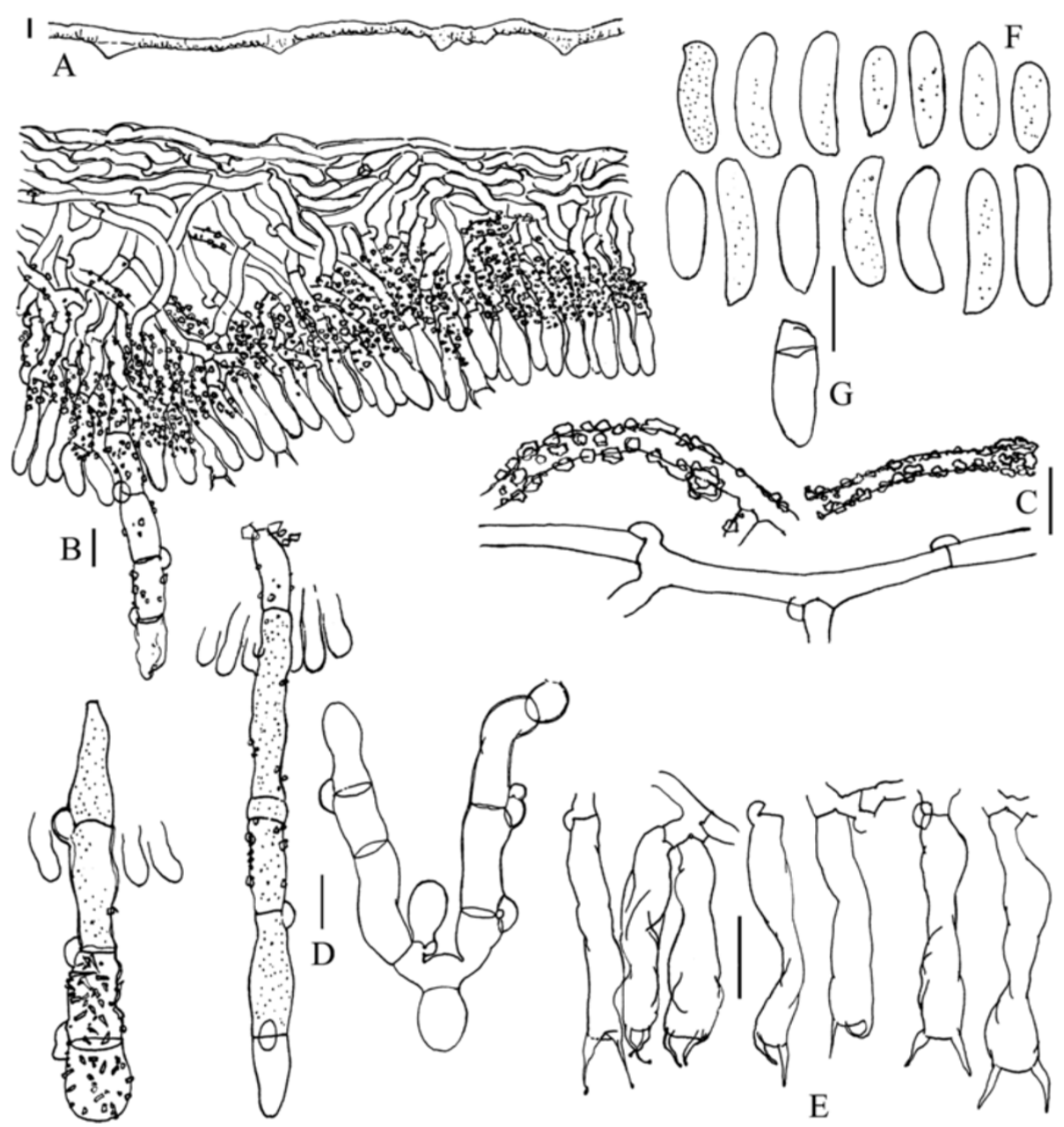

Figure 2 Micromorphology of Hyphoderma pinicola (TNM F13637). A, B, Vertical sections through basidioma; C, Naked and encrusted subicular hyphae; D, Two straight and one distorted septocystidia; E, Basidia; F, Normal basidiospores; G, Basidiospore with a false septum. Scale bars: for $\mathrm{A}=100 \mu \mathrm{m}$; for $\mathrm{B}-\mathrm{G}=10 \mu \mathrm{m}$.

\section{Remarks}

Another bi-sterigmate species from the H. setigerum complex, H. bisetigerum Boidin \& Gilles, was described from Madagascar (Boidin and Gilles, 2003). However, this species differs from $H$. pinicola in bearing shorter basidia, shorter basidiospores, and heavily encrusted septocystidia (see key). In the global survey of the H. setigerum complex (Nilsson et al., 2003), the largest spores (12-14.5 × 4.5$5 \mu \mathrm{m})$ were found in the material from Greenland; these however are shorter than in $H$. pinicola. According to a detailed morphological study of $H$. setigerum in Belarus and northwest Russia (Yurchenko and Zmitrovich, 2001), the largest spores do not exceed $14 \mu \mathrm{m}$ long, with averages from 7.3 to $11.2 \mu \mathrm{m}$. The average spore size in $H$. pinicola specimens was $15.1 \times 4.3 \mu \mathrm{m}$ (holotype), $14.4 \times 4.3 \mu \mathrm{m}$ (TNM F13635), and $14.1 \times 4.5 \mu \mathrm{m}$ (TNM F13643). The preference of growing on coniferous wood is rare for $H$. setigerum s.l., and it is a distinctive ecological feature of $H$. pinicola.

\section{Molecular phylogeny}

The 5.8S-ITS2 dataset analyzed by Bayesian analysis included 356 positions together with introduced gaps (99 positions in partial 5.8S, 86 of which were constant; 257 positions in complete ITS2, 66 of which were constant). MrModeltest suggested GTR $+\mathrm{I}+\mathrm{G}$ as the bestfit model of nucleotide evolution for $5.8 \mathrm{~S}+\mathrm{ITS} 2$, K80 for partial 5.8S, and GTR $+\mathrm{I}+\mathrm{G}$ for the whole dataset. The aligned datamatrix of partial $28 \mathrm{~S}$ sequences included 882 positions, of which 820 were constant. The best-fit model of nucleotide evolution suggested for it by MrModeltest was GTR + I + G.

Both phylograms generated using Bayesian approach (Figures 3 and 4) confirmed that $H$. pinicola belongs to the genus Hyphoderma. According to the phylogram based on 5.8S-ITS2 (Figure 3), three specimens of $H$. pinicola constitute a well-supported clade (with Bayesian posterior probability value, $\mathrm{PP}=1.00$ ) within the $H$. setigerum complex. The phylogram based on partial 28S (Figure 4) 


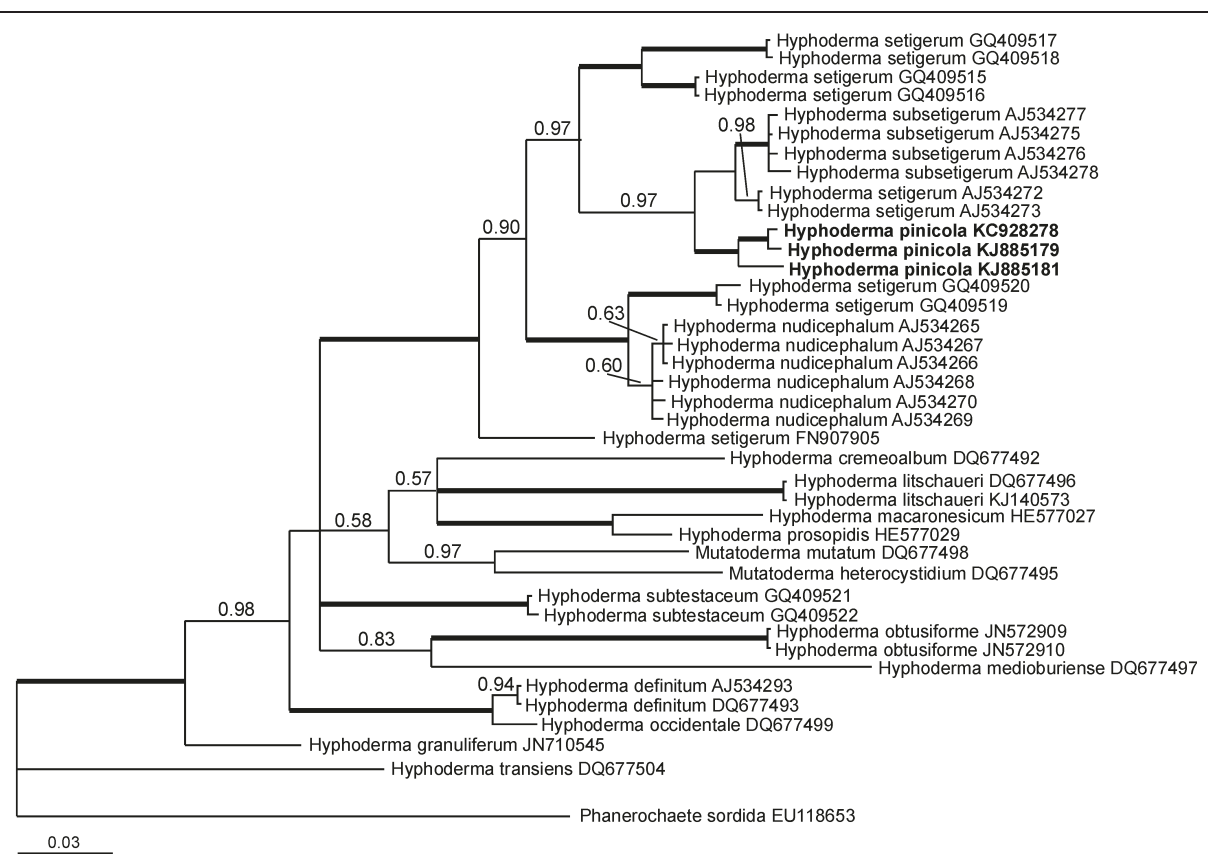

Figure 3 Phylogram obtained to reveal the phylogenetic position of Hyphoderma pinicola via Bayesian analysis (5.8S-ITS2 dataset). Numbers above branches denote Bayesian posterior probability (PP) value (if PP $\geq 0.50$ ). Thick branches have PP $\geq 0.99$. Scale bar for branch length indicates the number of nucleotide substitutions per site.

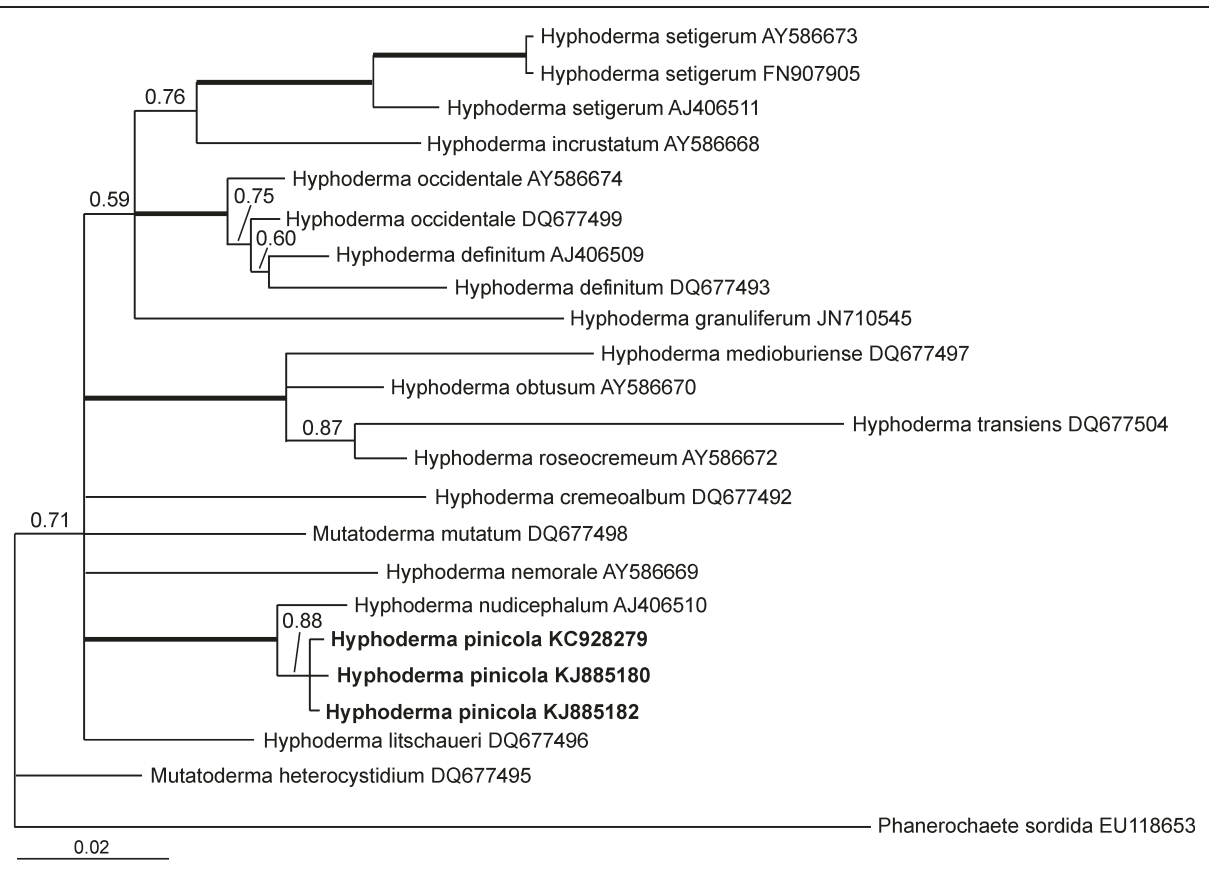

Figure 4 Phylogram obtained to reveal the phylogenetic position of Hyphoderma pinicola via Bayesian analysis (28S dataset). Numbers above branches denote Bayesian posterior probability (PP) value (if PP $\geq 0.50$ ). Thick branches have PP $\geq 0.99$. Scale bar for branch length indicates the number of nucleotide substitutions per site. 
demonstrates that three specimens of $H$. pinicola also constitute a separate clade ( $\mathrm{PP}=0.88$ ). They belong to a highly supported clade $(\mathrm{PP}=1.00)$ together with H. nudicephalum Gilb. \& M. Blackw. A high degree of molecular divergence in ITS and $28 \mathrm{~S}$ sequences supports specific status of $H$. pinicola.

\section{Discussion}

A test of the application of molecular phylogeny in taxonomy is whether there is consistency between classification schemes based on molecular characters and morphological traits. Our results demonstrate certain congruence between morphological study and ribosomal gene sequence analyses. The phylogram inferred from 5.8S-ITS2 shows $H$. pinicola as a member of $H$. setigerum complex. All specimens of the $H$. setigerum complex constitute a separate, strongly supported clade. However, the $H$. setigerum complex appeared to be not monophyletic according to 28S-based phylogram. This phylogram shows that $H$. pinicola and $H$. nudicephalum are separate from $H$. setigerum. Basal branching order in 28S-based phylogram is not strongly supported by Bayesian posterior probability values, indicating that phylogenetic differentiation within the genus is not deep.

The previous comprehensive phylogenetic study of the $H$. setigerum complex (Nilson et al., 2003) provided molecular grounds for recognition of $H$. nudicephalum and $H$. subsetigerum Sheng $\mathrm{H}$. Wu. These species were defined morphologically: by characteristic cystidia in H. nudicephalum (Gilbertson and Blackwell, 1988) and small spores in $H$. subsetigerum (Wu, 1997). However, more than ten clades and subgroups were recognized and considered at species rank within this complex. As Nilsson et al. (2003: 651) noted, H. subsetigerum known from Asia (subgroup $7 \mathrm{~B}$ ) and $H$. setigerum s.s. from Northern Europe (subgroup 7B, AJ534272, AJ534273) constitute two different species because of incompatibility, geographic isolation and differences in spore size. Hyphoderma pinicola constitutes the third species in this small clade, possessing distinctive features in morphology, host preference, and distribution. The clade composed of longspored specimens from Greenland is not only geographically, but also phylogenetically far from ' $H$. subsetigerum' clade (see Nilsson et al., 2003, Figure 1). This analysis revealed that the sister group to the ' $H$. subsetigerum' clade (i.e. the assemblage of $H$. pinicola, $H$. setigerum s.s., and $H$. subsetigerum) includes specimens of $H$. setigerum s.l. from Argentina (GQ409515, GQ409516) and South Africa (GQ409517, GQ409518). Both of these clades can be recognized as two independent species. Thus, after phylogenetic reconstructions, presumably new species from geographically separated areas appeared to be discriminated in highly supported clades on the basis of the 5.8SITS2 dataset only.
Two specimens of $H$. subtestaceum (Litsch.) Donk (GQ409521, GQ409522) were included in our phylogenetic study. According to Mycobank, H. subtestaceum is a synonym of $H$. setigerum. However, in the phylogram based on 5.8S-ITS2 sequences (Figure 3), these two specimens constitute a highly supported clade $(\mathrm{PP}=1.00)$ separate from the clade that includes the $H$. setigerum complex. These results suggest that specimens from North America, called H. subtestaceum, belong to an independent species.

\section{Conclusion}

Hyphoderma pinicola, known from Yunnan Province, China, and collected on dead wood of Pinus yunnanensis, represents the fifth named species of the $H$. setigerum complex.

\section{Competing interests}

The authors declare that they have no competing interests.

\section{Authors' contributions}

EY prepared description and illustration for the new taxon, performed phylogenetic analysis, and prepared the manuscript. SHW collected the specimens and provided preliminary identification, suggested the study topic, guided molecular lab work, examined the taxa used for phylogenetic study, and revised and prepared the manuscript for submission. Both authors read and approved the final manuscript.

\section{Acknowledgements}

This study was supported financially by Ministry of Science and Technology of ROC (grants NSC 98-2621-B-178-002-MY3 and NSC 101-2621-B-178-001-MY3). We are grateful to S.Z. Chen (TNM) for the help in managing herbarium specimens for this study and to Y.P. Chen for performing DNA extraction and amplification.

\section{Author details}

${ }^{1}$ Department of Biotechnology, Paleski State University, Dnyaprouskai flatylii str. 23, BY-225710 Pinsk, Belarus. ²Department of Biology, National Museum of Natural Science, Taichung 404, Taiwan.

Received: 20 July 2014 Accepted: 20 September 2014

Published online: 09 October 2014

\section{References}

Binder M, Justo A, Riley R, Salamov A, Lopez-Giraldez F, Sjökvist E, Copeland A Foster B, Sun H, Larsson E, Larsson K-H, Townsend J, Grigoriev IV, Hibbett DS (2013) Phylogenetic and phylogenomic overview of the Polyporales. Mycologia 105:1350-1373, doi:10.3852/13-003

Boidin J, Gilles G (2003) Homobasidiomycètes Aphyllophorales non porés à basides dominantes à 2 (3) stérigmates. Bull Soc Mycol Fr 119:1-17

Dai Y-C (2011) A revised checklist of corticioid and hydnoid fungi in China for 2010. Mycoscience 52:69-79, doi:10.1007/s10267-010-0068-1

Gilbertson RL, Blackwell M (1988) Some new or unusual corticioid fungi from the Gulf Coast Region. Mycotaxon 33:375-386

Katoh K, Asimenos G, Toh H (2009) Multiple alignment of DNA sequences with MAFFT. Methods Mol Biol 537:39-64, doi:10.1007/978-1-59745-251-9_3

Kirk P (ed) (2014) Index Fungorum. http://www.indexfungorum.org/Names/ Names.asp. Retrieved 29 Jun 2014

Kumar S, Tamura K, Nei M (2004) MEGA3: integrated software for Molecular Evolutionary Genetics Analysis and sequence alignment. Brief Bioinform 5:150-163, doi:10.1093/bib/5.2.150

Moncalvo JM, Lutzoni FM, Rehner SA, Johnson J, Vilgalys R (2000) Phylogenetic relationships of agaric fungi based on nuclear large subunit ribosomal DNA sequences. Syst Biol 49:278-305, doi:10.1093/sysbio/49.2.278 
Nilsson RH, Hallenberg N, Nordén B, Maekawa N, Wu S-H (2003) Phylogeography of Hyphoderma setigerum (Basidiomycota) in the Northern Hemisphere. Mycol Res 107:645-652, doi:10.1017/S0953756203007925

Nylander JAA (2004) MrModeltest v2. Program distributed by the author. Evolutionary Biology Center, Uppsala University, Uppsala

Posada D, Buckley TR (2004) Model selection and model averaging in phylogenetics: advantages of the Akaike Information Criterion and Bayesian approaches over likelihood ratio tests. Syst Biol 53:793-808, doi:10.1080/ 10635150490522304

Ronquist F, Huelsenbeck JP (2003) MrBayes 3: Bayesian phylogenetic inference under mixed models. Bioinformatics 19:1572-1574, doi:10.1093/ bioinformatics/btg180

Swofford DL (2002) PAUP*: phylogenetic analysis using parsimony (*and other methods), vol 4. Sinauer Associates, Sunderland

White TJ, Bruns T, Lee S, Taylor J (1990) Amplification and direct sequencing of fungal ribosomal RNA genes for phylogenetics. In: Innis MA, Innis MA, Gelfand DH, Sninsky JJ, White TJ (eds) PCR protocols: A guide to methods and applications. Academic Press, New York, pp 315-322

Wu SH (1997) New species of Hyphoderma from Taiwan. Mycologia 89:132-140, doi:10.2307/3761182

Wu SH, Wang DM, Tschen E (2007) Brunneocorticium pyriforme, a new corticioid fungal genus and species belonging to the euagarics clade. Mycologia 99:302-309, doi:10.3852/mycologia.99.2.302

Yurchenko EO, Zmitrovich IV (2001) Variability of Hyphoderma setigerum (Corticiaceae s.l., Basidiomycetes) in Belarus and northwest Russia. Mycotaxon 78:423-434

doi:10.1186/s40529-014-0071-5

Cite this article as: Yurchenko and Wu: Hyphoderma pinicola sp. nov. of H. setigerum complex (Basidiomycota) from Yunnan, China. Botanical Studies 2014 55:71.

\section{Submit your manuscript to a SpringerOpen ${ }^{\circ}$ journal and benefit from:}

- Convenient online submission

- Rigorous peer review

- Immediate publication on acceptance

- Open access: articles freely available online

- High visibility within the field

- Retaining the copyright to your article

Submit your next manuscript at $>$ springeropen.com 